\title{
A Multi-Fluorescent DNA/Graphene Oxide Conjugate Sensor for Signature-Based Protein Discrimination
}

\author{
Shunsuke Tomita ${ }^{1, *}$ (D), Sayaka Ishihara ${ }^{1}$ and Ryoji Kurita ${ }^{1,2, *}$ \\ 1 Biomedical Research Institute, National Institute of Advanced Industrial Science and Technology, \\ and DAILAB, 1-1-1 Higashi, Tsukuba, Ibaraki 305-8566, Japan; ishihara.sayaka@aist.go.jp \\ 2 Faculty of Pure and Applied Sciences, University of Tsukuba, 1-1-1 Tennodai, Tsukuba, \\ Ibaraki 305-8573, Japan \\ * Correspondence: s.tomita@aist.go.jp (S.T.); r.kurita@aist.go.jp (R.K.); Tel.: +81-29-861-2634 (S.T.)
}

Received: 25 July 2017; Accepted: 19 September 2017; Published: 23 September 2017

\begin{abstract}
Signature-based protein sensing has recently emerged as a promising prospective alternative to conventional lock-and-key methods. However, most of the current examples require the measurement of optical signals from spatially-separated materials for the generation of signatures. Herein, we present a new approach for the construction of multi-fluorescent sensing systems with high accessibility and tunability, which allows generating protein fluorescent signatures from a single microplate well. This approach is based on conjugates between nano-graphene oxide (nGO) and three single-stranded DNAs (ssDNAs) that exhibit different sequences and fluorophores. Initially, the three fluorophore-modified ssDNAs were quenched simultaneously by binding to $\mathrm{nGO}$. Subsequent addition of analyte proteins caused a partial recovery in fluorescent intensity of the individual ssDNAs. Based on this scheme, we have succeeded in acquiring fluorescence signatures unique to (i) ten proteins that differ with respect to $\mathrm{pI}$ and molecular weight and (ii) biochemical marker proteins in the presence of interferent human serum. Pattern-recognition methods demonstrated high levels of discrimination for this system. The high discriminatory power and simple format of this sensor system should enable an easy and fast evaluation of proteins and protein mixtures.
\end{abstract}

Keywords: DNAs; nano-graphene oxide; proteins; multivariate analysis; biosensors

\section{Introduction}

The accurate identification of proteins is of critical importance for the understanding of a variety of biological processes and diseases [1,2]. Although the most frequently used lock-and-key approaches are successful [1-3], they often suffer from difficulties in obtaining specific receptors, such as antibodies and aptamers, for each target protein. In the past decade, signature-based sensing has emerged as a promising prospective alternative to lock-and-key specific recognition [4,5]. Signature-based sensors feature a group of "cross-reactive" materials that can interact in different ways with target proteins. Cross-reactive materials are usually integrated or complexed with reporter units (e.g., fluorescent and absorbent moieties) to give unique "multidimensional" optical signatures for individual proteins. A subsequent pattern-recognition of the thus-obtained signatures enables the accurate identification of proteins. Signature-based sensing has been successfully employed for the detection of proteins in dilute solutions [6-17] and in biological matrices [18-27]. However, most of the current examples require the measurement of optical signals from spatially-separated materials for the generation of signatures, e.g., in multiple wells of a microplate, which significantly limits the scope for applications that depend on a simple and rapid identification of proteins.

To address the aforementioned drawbacks, "multichannel" signature-based protein sensing systems have recently been developed, and these are based predominantly on two strategies: (i) the 
measurement of different optical properties from one type of material, and (ii) the measurement of a single optical property from one type of material or from a mixture of materials. The former so-called "lab-on-a-molecule" strategy uses different instruments to detect e.g., the fluorescence, phosphorescence, fluorescence polarization, and/or light-scattering intensity of materials, such as quantum dots [28-30] and graphene oxide (GO) [31]. Conversely, the latter strategy does not require multiple instruments for the readout of optical signatures [32], which significantly decreases the complexity and duration of the optical measurements. For example, three quantum dots with spectral resolvable fluorescence have been used to generate fluorescent signatures of proteins from a single microplate well [33]. Individual quantum dots can be synthetically modified with different functional groups, and subsequently be quenched simultaneously via conjugation with bromophenol blue. This sensing platform is capable of discriminating ten proteins and eight cell lines. Rotello et al. have applied a nanoparticle-based protein identification system $[6,18,19]$ to multi-fluorescent sensing: quenched conjugates between gold-nanoparticles and three fluorescent proteins have been used for the detection of bacterial biofilms [34], mammalian cells [35,36], and drug-induced changes on cell surfaces [37]. However, these approaches still require laborious synthetic [33] or protein expression protocols [34-37], which represents a viable obstacle to adapt and extend this strategy to practical applications.

We envisioned that fluorophore-modified single-stranded DNA (ssDNA) could be suitable for the construction of multi-fluorescent sensing systems, as virtually any sequence of ssDNA can be synthesized commercially in high purity and labeled with fluorophores at low cost. This accessibility and tunability should create the structurally-diverse sensing elements necessary for high levels of discrimination. Recently, Pei et al. [38] and our group [39] have developed arrays of fluorophore-modified ssDNA quenched via noncovalent complexation with nano-graphene oxide (nGO) for the identification of proteins based on measurements of spatially separated conjugates. Encouraged by these studies, we have used conjugates between nGO and three ssDNAs with different sequences and different fluorophores in order to construct a sensing system that affords unique protein fluorescence signatures from a single microplate well (Figure 1). In this system, three fluorophore-modified ssDNAs are quenched simultaneously via complexation with nGO (Figure 1A). The subsequent addition of proteins causes a disruption of the conjugates via competitive interactions with individual ssDNAs, and in some cases with nGO. The use of sequentially- and structurally-diverse ssDNAs results in the unique release of ssDNAs from the conjugates due to the different binding affinities between the individual ssDNAs and the proteins. A multichannel fluorescence reading then allows generating signatures that reflect the amount of released ssDNA (Figure 1B). Data interpretation through pattern recognition methods demonstrated that this system shows high levels of discrimination for a variety of proteins.

A

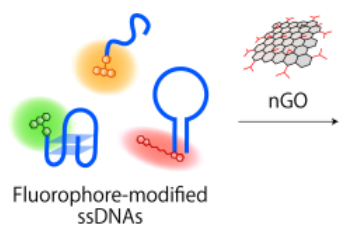

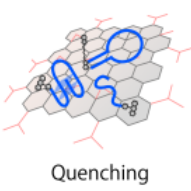

Quenching
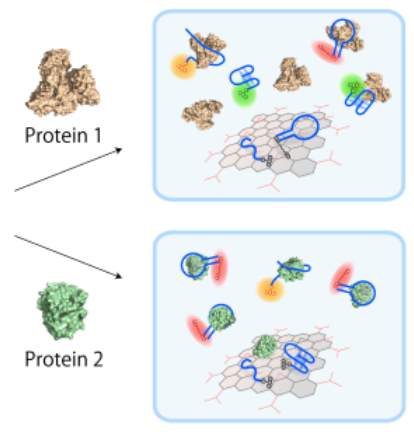

Differential multi-fluorescences in a single well of a microplate

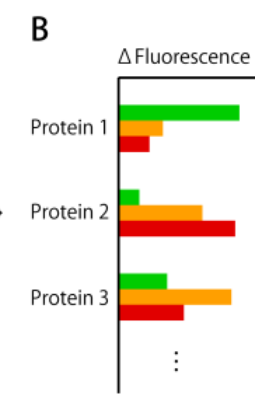

Figure 1. Schematic representation of the multi-fluorescent ssDNAs/nGO sensor system presented in this study. (A) Structurally different ssDNAs that contain different fluorophores are initially quenched simultaneously by complexation with nGO. The conjugates subsequently interact with different proteins in different ways, (B) which results in the generation of multicolor fluorescence signatures. 


\section{Materials and Methods}

\subsection{Materials}

Nano-graphene oxide ( $\mathrm{nGO}$; width $=90 \pm 15 \mathrm{~nm}$; thickness $=1 \mathrm{~nm}$ ) dispersed in water was obtained from EM Japan Co., Ltd (Tokyo, Japan). ssDNAs labeled with carboxyfluorescein (FAM) at the $3^{\prime}$ terminus (P1-FAM), with carboxytetramethylrhodamine (TAMRA) at the $3^{\prime}$ terminus (P2-TAMRA), or with indodicarbocyanine (Cy5) at the $5^{\prime}$ terminus (P3-Cy5) were synthesized and purified by Eurofins Genomics (Ebersberg, Germany). Pepsin from porcine stomach (Pep), $\beta$-galactosidase from Escherichia coli (Gal), albumin from bovine serum (BSA), catalase from bovine liver (Cat), transferrin from human serum (Tra), myoglobin from equine heart (Myo), $\alpha$-chymotrypsinogen from bovine pancreas (Chy), lysozyme from hen egg white (Lys), and cytochrome c from horse heart (Cyt) were obtained from Sigma Chemical Co. (St. Louis, MO, USA). Immunoglobulin G from human serum (IgG) was obtained from Equitech-Bio, Inc. (Kerrville, TX, USA). Phosphate-buffered saline (PBS) was obtained from Wako Pure Chemical Ind. (Osaka, Japan).

\subsection{Fluorescence Quenching Study}

Fluorescence measurements were performed on a Spectra max GEMINI XPS (Molecular devices, Sunnyvale, CA, USA). Solutions $(200 \mu \mathrm{L})$ containing 20 nM P1-FAM, 20 nM P2-TAMRA, 20 nM P3-Cy5, and 0-160 $\mathrm{gg} / \mathrm{mL}$ nGO in PBS buffer $(\mathrm{pH}=7.4)$ were prepared in each well of a 96-well plate (96-well black flat-bottom polystyrene NBS microplates; Corning Inc., Corning, NY, USA) using a PIPETMAX system (Gilson Inc., Middleton, WI, USA). After incubation $\left(T=30^{\circ} \mathrm{C}, t=10 \mathrm{~min}\right)$, fluorescence spectra were recorded at $T=30^{\circ} \mathrm{C}$ using three different excitation wavelengths (P1-FAM: $\lambda_{\mathrm{ex}}=480 \mathrm{~nm}, \lambda_{\mathrm{em}}=520-595 \mathrm{~nm}$; P2-TAMRA: $\lambda_{\mathrm{ex}}=530 \mathrm{~nm}, \lambda_{\mathrm{em}}=575-665 \mathrm{~nm} ;$ P3-Cy5: $\lambda_{\mathrm{ex}}=630 \mathrm{~nm}$, $\left.\lambda_{\mathrm{em}}=660-750 \mathrm{~nm}\right)$. Binding isotherms were produced based on changes in the fluorescence intensity at $\lambda_{\mathrm{em}}=519 \mathrm{~nm}(\mathbf{P 1}-\mathrm{FAM}), 579 \mathrm{~nm}$ (P2-TAMRA), and $664 \mathrm{~nm}($ P3-Cy5).

\subsection{Signature-Based Sensing}

Solutions $(180 \mu \mathrm{L})$ containing 22.2 nM P1-FAM, 22.2 nM P2-TAMRA, 22.2 nM P3-Cy5, and 111.1 $\mu \mathrm{g} / \mathrm{mL} \mathrm{nGO}$ in PBS buffer $(\mathrm{pH}=7.4$ ) were prepared in each well of a 96-well plate using a PIPETMAX system. After incubation $\left(T=30^{\circ} \mathrm{C}, t=10 \mathrm{~min}\right)$, the fluorescence intensities were collected at seven different channels (vide infra). Subsequently, aliquots $(20 \mu \mathrm{L})$ of $150 \mu \mathrm{g} / \mathrm{mL}$ proteins in PBS $(\mathrm{pH}=7.4)$ were added to each well, before the fluorescence intensities were recorded after incubation $\left(T=30^{\circ} \mathrm{C}\right.$, $t=10 \mathrm{~min}$ ). For the sensing of protein in the presence of interferents, human serum that was diluted 3000-fold with PBS ( $\mathrm{pH}=7.4$ ) was used as a solvent. This process was repeated six times to generate a training data matrix consisting of 7 channels $\times 6$ replicates. The raw data matrix was processed using linear discriminant analysis (LDA) and hierarchical clustering analysis (HCA) in SYSTAT 13 (Systat Software Inc., San Jose, CA, USA). For a blind test, the same process was repeated six times to generate a test data matrix. The test data were classified into groups generated by the training matrix according to their shortest Mahalanobis distances.

\section{Results and Discussion}

\subsection{Construction of a Multi-Fluorescent ssDNAs/nGO Sensor}

To construct a multi-fluorescent ssDNAs/nGO sensor, we designed three fluorophore-modified ssDNAs (Figure 2A); P1-FAM: a quadraplex-formative sequence with FAM $\left(\lambda_{\text {ex } \max } / \lambda_{\text {em max }}=\right.$ $495 \mathrm{~nm} / 518 \mathrm{~nm}) ;$ P2-TAMRA: a simple repeated sequence with TAMRA $\left(\lambda_{\mathrm{ex} \max } / \lambda_{\mathrm{em} \max }=\right.$ $555 \mathrm{~nm} / 575 \mathrm{~nm})$; P3-Cy5: a hairpin-structure-formative sequence with Cy5 $\left(\lambda_{\mathrm{ex} \max } / \lambda_{\mathrm{em} \max }=\right.$ $645 \mathrm{~nm} / 660 \mathrm{~nm})$. These ssDNAs bear different sequences, and two of these can fold into different higher-order structures, which were expected to impart the individual elements of the sensor system 
with differential cross-reactivity [38,39]. In addition, well-separated absorption and emission spectra allow the readout of independent emissions of the fluorophores (Figure 2B).

A

\begin{tabular}{|c|c|c|c|c|}
\hline $\begin{array}{l}\text { P1-FAM } \\
\text { P2-TAMRA } \\
\text { P3-Сy5 }\end{array}$ & $\begin{array}{l}\text { (quadraplex) } \\
\text { (simple repeated) } \\
\text { (hairpin) }\end{array}$ & $\begin{array}{l}5^{\prime}- \\
5^{\prime}- \\
5^{\prime}-\text { Cy5- }\end{array}$ & $\begin{array}{l}\text { GGT TGG TGT GGT TGG } \\
\text { CCC CCC CCC CCC CCC CCC } \\
\text { ACG GCA TGG TGG GCG TCG T }\end{array}$ & $\begin{array}{l}- \text { FAM }-3^{\prime} \\
\text {-TAMRA-3' } \\
-3^{\prime}\end{array}$ \\
\hline
\end{tabular}

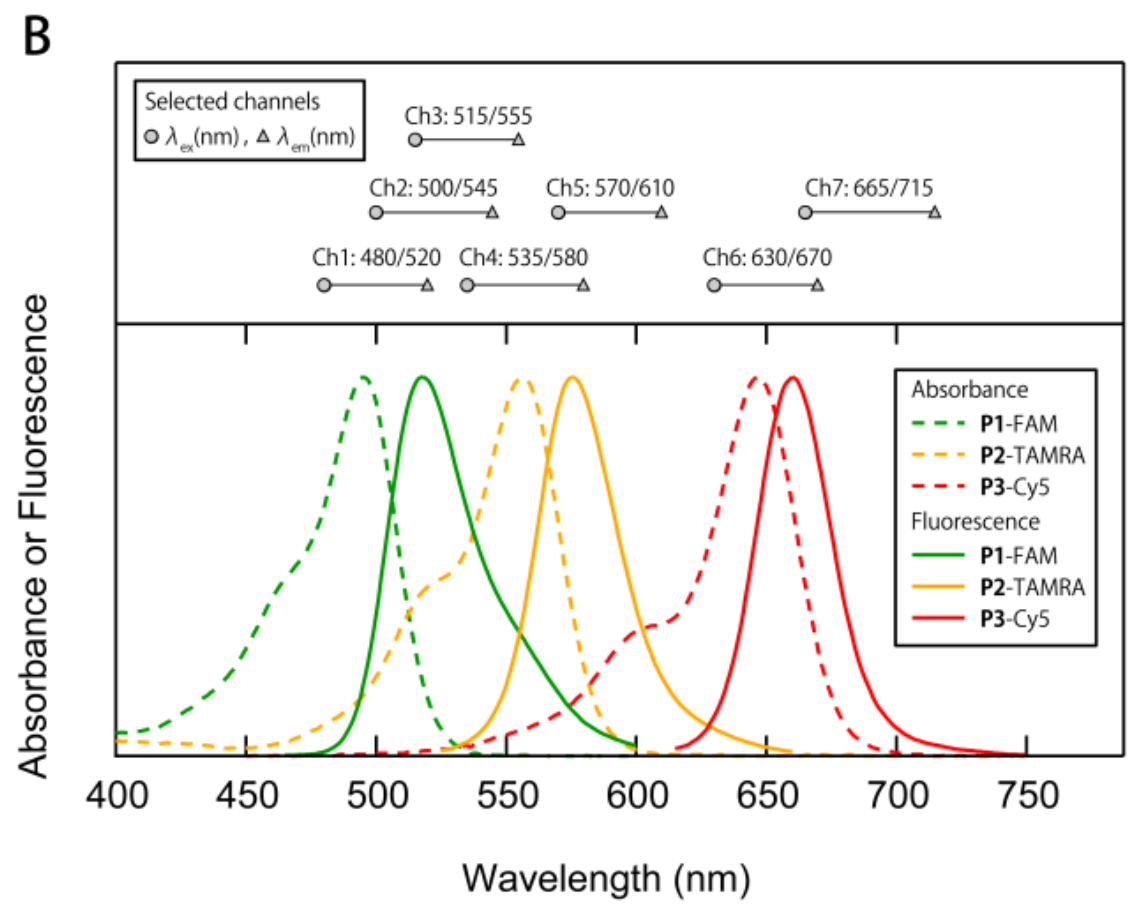

Figure 2. Absorption and fluorescence properties of the fluorophore-modified ssDNAs P1-FAM, P2-TAMRA, and P3-Cy5. (A) Sequence of the three ssDNAs and the modified fluorophores. (B) Normalized UV-VIS absorption and emission spectra of P1-FAM, P2-TAMRA, and P3-Cy5 in PBS $(\mathrm{pH}=7.4)$. The $\lambda_{\mathrm{ex}} / \lambda_{\mathrm{em}}$ combinations to acquire fluorescence signatures are shown in the upper panel.

Initially, a fluorescence titration of nGO was carried out on an equimolar mixture of the three ssDNAs $(20 \mathrm{nM})$ to examine whether $\mathrm{nGO}$ is able to quench the fluorescence of the ssDNAs simultaneously. For instance, the fluorescence emission of P2-TAMRA can be observed dominantly when excited at $535 \mathrm{~nm}$ and detected at $579 \mathrm{~nm}$. As shown in Figure 3A, the addition of nGO to a solution containing the three ssDNAs resulted in a concentration-dependent quenching of P2-TAMRA. Although P1-FAM and P3-Cy5 showed a similar pronounced decrease in fluorescence emission (Figure 3B and Figure S1), the corresponding quenching efficacies were lower than that of P2-TAMRA. This may be attributed to the shielding of nucleobases in P1-FAM and P3-Cy5, caused by the DNA folding, which could hamper $\pi-\pi$ stacking interactions with nGO [40]. Therefore, in the following sensing experiments we used a binding ratio that provides high fluorescence quenching for all ssDNAs and minimal reproducible responses with the addition of $15 \mu \mathrm{g} / \mathrm{mL}$ proteins (Figure S2), i.e., $20 \mathrm{nM}$ ssDNAs and $100 \mu \mathrm{g} / \mathrm{mL}$ nGO. 
A

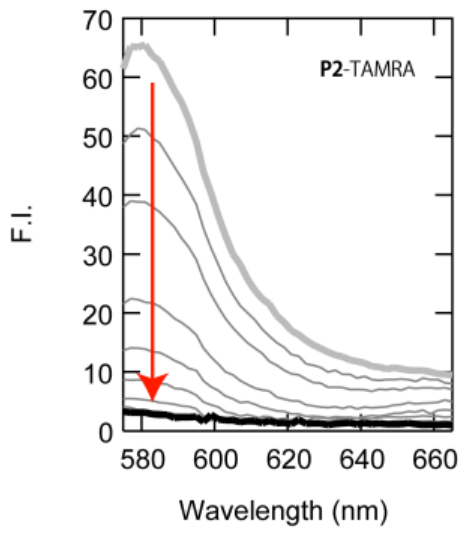

B

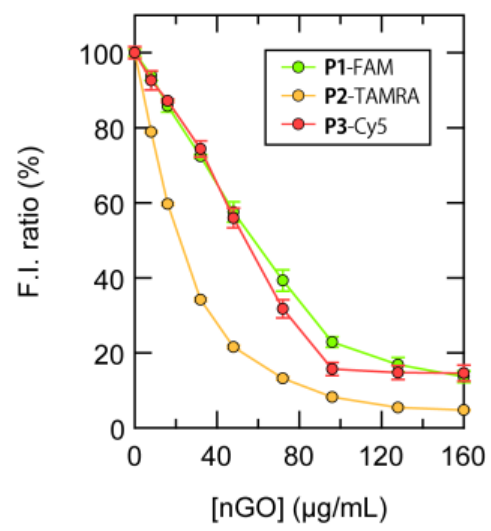

Figure 3. Preparation of ssDNAs/nGO conjugates. (A) Changes in the emission spectra corresponding predominantly to P2-TAMRA $\left(\lambda_{\mathrm{ex}}=535 \mathrm{~nm}\right)$ and $(\mathbf{B})$ the fluorescence ratio of $20 \mathrm{nM}$ fluorophore-modified ssDNAs in the presence of different concentrations of nGO in PBS ( $\mathrm{pH}=7.4)$; P1-FAM: $\lambda_{\mathrm{ex}}=480 \mathrm{~nm}, \lambda_{\mathrm{em}}=519 \mathrm{~nm}$; P2-TAMRA: $\lambda_{\mathrm{ex}}=535 \mathrm{~nm}, \lambda_{\mathrm{em}}=579 \mathrm{~nm}$; P3-Cy5: $\lambda_{\mathrm{ex}}=630 \mathrm{~nm}$, $\lambda_{\mathrm{em}}=664 \mathrm{~nm}$.

\subsection{Multi-Fluorescent Signature-Based Protein Sensing}

Subsequently, we tested the ability of the multi-fluorescent ssDNAs/nGO sensor to generate fluorescence signatures of proteins. For that purpose, ten proteins that vary in size and surface charges were chosen as sensing targets (Table 1). Each protein solution $(20 \mu \mathrm{L})$ in PBS $(\mathrm{pH}=7.4)$ was mixed with solutions $(180 \mu \mathrm{L})$ of ssDNAs/nGO conjugates in PBS $(\mathrm{pH}=7.4)$ to reach a final concentration of $15 \mu \mathrm{g} / \mathrm{mL}$ protein in a 96-well microplate. The fluorescence signals from individual wells were recorded as $\left(I-I_{0}\right)$ at seven different channels (Figure 2B), generating a data matrix of 7 channels $\times 10$ proteins $\times 6$ replicates (Table S1). Four channels provided almost independent emissions of P1-FAM (Ch1), P2-TAMRA (Ch4), and P3-Cy5 (Ch6 and Ch7). Conversely, the other three channels (Ch2, $\mathrm{Ch} 3$, and Ch5) were likely located between the absorption and emission spectra of two of the three fluorophores, which should allow investigating the effectiveness of using spectral crosstalk.

Table 1. Properties of the proteins used in this study as sensing targets.

\begin{tabular}{ccccc}
\hline Protein & Source & Abbreviation & $\boldsymbol{M}_{\boldsymbol{w}}$ & pI \\
\hline Pepsin & Porcine stomach & Pep & 35,000 & 3.2 \\
$\beta$-Galactosidase & Escherichia coli & Gal & 465,000 & 5.1 \\
Albumin & Bovine serum & BSA & 66,000 & 5.6 \\
Catalase & Bovine liver & Cat & 230,000 & 6.4 \\
Transferrin & Human serum & Tra & 75,000 & 6.7 \\
Immunoglobulin G & Human serum & IgG & 143,000 & 7.3 \\
Myoglobin & Equine heart & Myo & 18,000 & 7.4 \\
$\alpha$-Chymotrypsinogen & Bovine pancreas & Chy & 26,000 & 8.5 \\
Lysozyme & Hen egg white & Lys & 14,000 & 9.2 \\
Cytchrome c & Horse heart & Cyt & 12,000 & 9.5 \\
\hline
\end{tabular}

The thus-obtained fluorescence signatures (Figure 4A) likely show good reproducibility for the analyte proteins. These signatures were then subjected to an LDA in order to examine whether the individual signatures differ significantly. LDA is a supervised pattern recognition algorithm that provides a graphical output that offers insight into the clustering of the data and information on the classification ability [4]. A linear discriminant score plot revealed ten well-separated clusters corresponding to the individual proteins (Figure 4B). In this plot, each point represents the fluorescence 
signature of a single analyte protein. The first discriminant score, i.e., Score (1), provided the best discrimination among the classes, which accounted for $75.6 \%$ of the total variance. We expected basic proteins such as Lys $(\mathrm{pI}=9.2)$ and Cyt $(\mathrm{pI}=9.5)$ to exhibit a higher binding affinity than neutral or acidic proteins, as both $\mathrm{nGO}$ and the ssDNAs are negatively charged at $\mathrm{pH}=7.4$. However, the first discriminant scores showed almost no correlation with the pIs of the proteins $(r=-0.17)$. Considering the equally low correlation with the protein size $(r=0.18)$, the sum of interactions regarding various characteristics, such as electrostatic and aromatic properties, hydrophobicity, surface heterogeneity and morphology, may possibly be responsible for the output as fluorescence signatures.

A

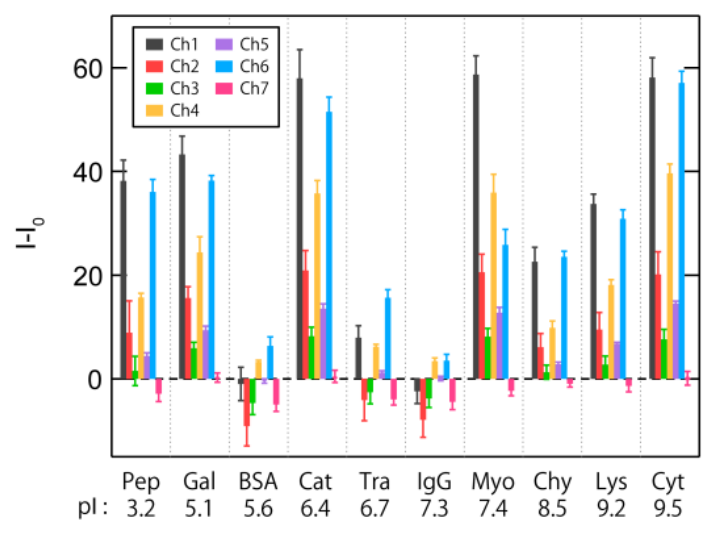

B

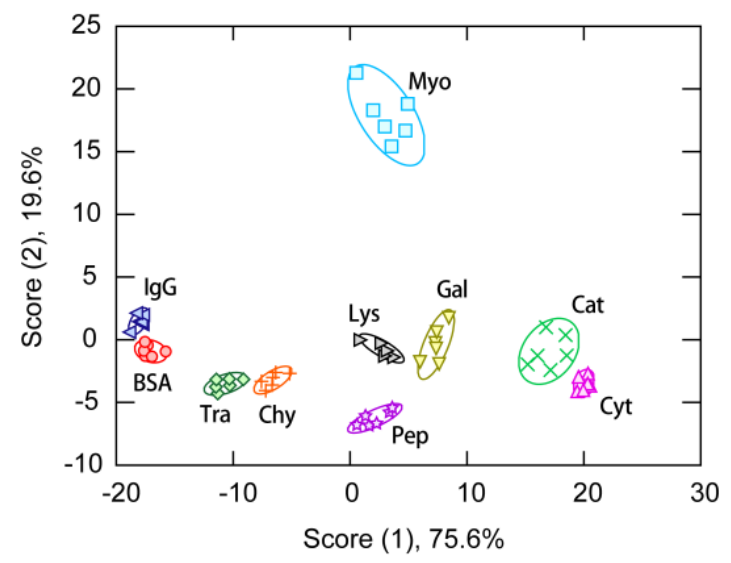

Figure 4. Protein identification using the multichannel ssDNAs/nGO sensing system presented in this study. (A) Signatures of changes in the fluorescence intensity upon addition of protein solutions $(15 \mu \mathrm{g} / \mathrm{mL})$ from a sensor consisting of $100 \mu \mathrm{g} / \mathrm{mL} \mathrm{nGO}$ and $20 \mathrm{nM}$ of the three fluorophore-modified ssDNAs. Values are shown as mean values $\pm \operatorname{SD}(n=6)$. (B) Discriminant score plot for protein solutions $(15 \mu \mathrm{g} / \mathrm{mL})$ obtained from the seven-channel system, whereby ellipsoids represent confidence intervals $( \pm 1 \mathrm{SD})$ for the individual analytes.

Then, a leave-one-out cross-validation analysis, the so-called jackknife classification procedure [41], was performed to determine the classification potential of the multi-fluorescent ssDNAs/nGO conjugate sensor. Using a single channel afforded classification accuracies of $50 \%$, $35 \%, 33 \%, 63 \%, 75 \%, 70 \%$, and $33 \%$ for Ch1 to Ch7, respectively, while the accuracy increased to $97 \%$ when using all seven channels (Table 2). Thus, it can be concluded that the sensor can acquire sufficient information to discriminate a variety of proteins from a single well. This system was able to detect ten different proteins at $15 \mu \mathrm{g} / \mathrm{mL}$, ranging from $32 \mathrm{nM}$ (Gal) to $1.3 \mu \mathrm{M}(\mathrm{Cyt})$, which is comparable to the performance of a previously reported multi-fluorescent signature-based protein sensor [33]. It should be noted that using merely three channels that are selective to individual fluorophores (Ch1, Ch4 and Ch6) afforded a comparable classification accuracy (98\%; Table 2), while a partial overlap between confidence ellipses was observed in the discriminant score plot (Figure S3). The accuracy for IgG did not reach $100 \%$ in all cases shown in Table 2, possibly due to the lower responses of ssDNAs/nGO conjugates compared to other proteins (Figure 4A). The slight increase in accuracy for BSA upon decreasing the number of channels may be attributed to the higher levels of noise in Ch2, Ch3, Ch5, and Ch7. 
Table 2. Classification accuracy of the multichannel ssDNAs/nGO sensor presented in this study.

\begin{tabular}{|c|c|c|c|c|c|c|c|c|c|c|c|c|c|c|c|c|c|}
\hline \multicolumn{7}{|c|}{ Selected Channels } & \multicolumn{11}{|c|}{$\%$ Correct } \\
\hline Ch1 & Ch2 & Ch3 & Ch4 & Ch5 & Che & $\mathrm{Ch}^{2}$ & BSA & Cat & Chy & $\mathrm{Cy}$ & $\mathrm{Ga}$ & IgG & Lys & Myo & Tra & Pep & Total \\
\hline & & & & & & & 50 & 0 & 100 & 0 & 83 & 50 & 83 & 17 & 100 & 17 & 50 \\
\hline & & & & & & & 67 & 17 & 50 & 17 & 83 & 33 & 17 & 0 & 67 & 0 & 35 \\
\hline & & & & & & & 67 & 17 & 17 & 33 & 67 & 33 & 50 & 17 & 33 & 0 & 33 \\
\hline & & & & & & & 50 & 0 & 100 & 67 & 67 & 67 & 83 & 0 & 100 & 100 & 63 \\
\hline & & & & & & & 67 & 0 & 100 & 83 & 100 & 83 & 100 & 50 & 83 & 83 & 75 \\
\hline & & & & & & & 67 & 67 & 67 & 83 & 83 & 83 & 67 & 33 & 100 & 50 & 70 \\
\hline & & & & & & & 50 & 83 & 33 & 17 & 17 & 17 & 33 & 50 & 0 & 33 & 33 \\
\hline & & & & & & & 100 & 100 & 100 & 100 & 100 & 83 & 100 & 100 & 100 & 100 & 98 \\
\hline & & & & & & & 83 & 100 & 100 & 100 & 100 & 83 & 100 & 100 & 100 & 100 & 97 \\
\hline
\end{tabular}

Thereafter, we used 60 newly-prepared samples for a blind test, and the new cases were assigned to proteins according to their shortest Mahalanobis distances. Only four samples were misclassified when using seven channels, affording a classification accuracy of 93\% (Table S2). The accuracy only slightly decreased to $88 \%$ when using merely Ch1, Ch4, and Ch6 (Table S2). These results suggest that it should be important to read out individual ssDNAs independently in the discrimination of proteins. It is possible that the high contributions of $\mathrm{Ch} 1, \mathrm{Ch} 4$, and $\mathrm{Ch} 6$ for protein discrimination is partly due to the higher magnitude in response compared to other channels (Figure 4A).

\subsection{Exploraion of Effective Sensing Channels for the Discrimination of Proteins}

In order to gain further insight into the effective selection of channels, we investigated the relevance of individual channels on the generation of fluorescence signatures using HCA, which determines clusters on the basis of the Euclidean distances between elements of a dataset. Therein, each channel was standardized prior to the analysis based on the following equation: $z=(x-\mu) / \sigma$, wherein $z$ is the standardized score, $x$ the raw response $\left(I-I_{0}\right), \mu$ the mean value of the population, and $\sigma$ the standard deviation of the population. Three clusters were observed (Figure 5), i.e., cluster 1 includes Ch1-Ch3, cluster 2 includes Ch4 and Ch5, while cluster 3 includes Ch6 and Ch7. This result indicates a low correlation between channels included in each cluster. As estimated from Figure 2B, $\mathrm{Ch} 2$ and Ch5 primarily read out the fluorescence of P1-FAM and P2-TAMRA, respectively. Hence, each cluster corresponds most likely to individual fluorophore-modified ssDNAs, suggesting that the use of different sequences and higher-order structures of ssDNA induce diverse cross-reactivity, which is a key feature for the generation of differential signatures. In their entirety, these results suggest that acquiring independent emissions of P1-FAM, P2-TAMRA, and P3-Cy5 is critical to design accurate multi-fluorescent sensing systems, which is consistent with the results from the Jackknife classification and the blind test (Table 2 and Table S2).

Note that the properties of nGO should be considered to construct sensing systems with higher discrimination capability, as the interactions between $\mathrm{nGO}$ and proteins may play a partial role in the generation of fluorescence signatures. Given the recent progress in GO research, it has not only become possible to produce GO at lower costs and on a larger scale [42,43], but also to control its size, defects, and surface functionality [44-46]. As GO with different characteristics interact differently with human cells and proteins $[44,46]$, an optimization of these characteristics should improve the discrimination capability of the system. 


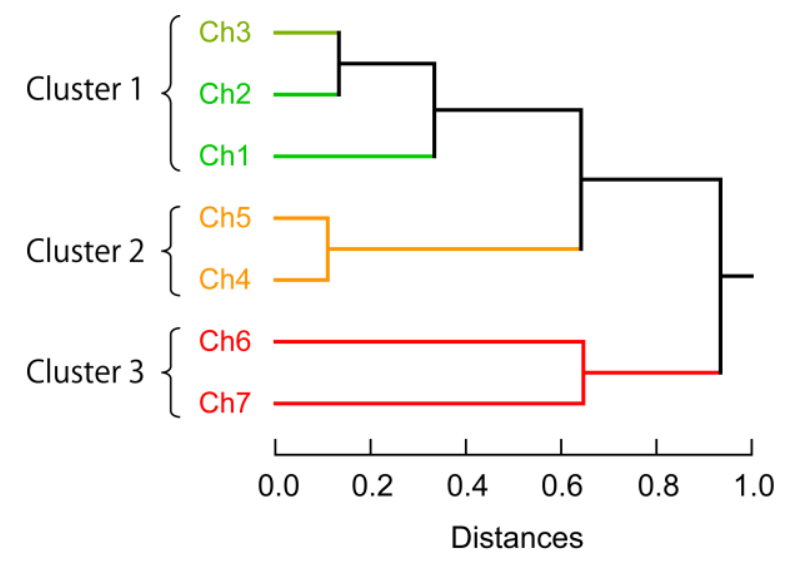

Figure 5. Clustering analysis of the discriminative channels of the multi-fluorescent ssDNAs/nGO sensor presented in this study. A hierarchical clustering dendrogram was created based on the Euclidean distances using the Ward method and a dataset of 7 channels $\times 10$ analytes $\times 6$ replicates. P1-FAM is primarily excited by Ch1 and Ch2; P2-TAMRA is primarily excited by Ch4 and Ch5; P3-Cy5 is primarily excited by $\mathrm{Ch} 6$ and $\mathrm{Ch} 7$.

\subsection{Protein Sensing in the Presence of Human Serum}

The performance of this sensing system was further evaluated for the identification of two different proteins (Cat and Myo) in the presence of interferent human serum. An estimated >10,000 proteins are present in human serum [47], generating a challenging, complex matrix. It has been suggested that serum levels of Cat [48] and Myo [49,50] could potentially be used as biochemical markers for particular diseases. Using the seven-channel system, 100\% discrimination accuracy based on the jackknife classification was achieved for different concentrations of Cat $(0-5 \mu \mathrm{g} / \mathrm{mL})$ (Figure 6A), and samples containing Cat and/or Myo with a total concentration of $5 \mu \mathrm{g} / \mathrm{mL}$ (Figure 6B). Cat clusters moved along the $\mathrm{x}$-axis with increasing concentration (Figure 6A), while the 1:1 mixture of Cat and Myo was located between these components (Figure 6B). These results indicate the potential of this method for the detection of proteins in solutions containing complex interferents.

A

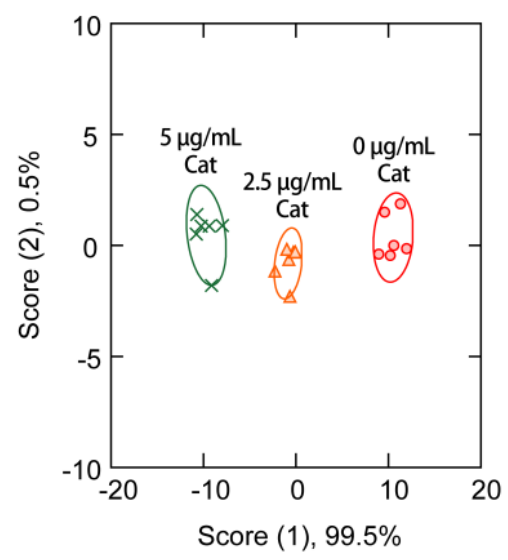

B

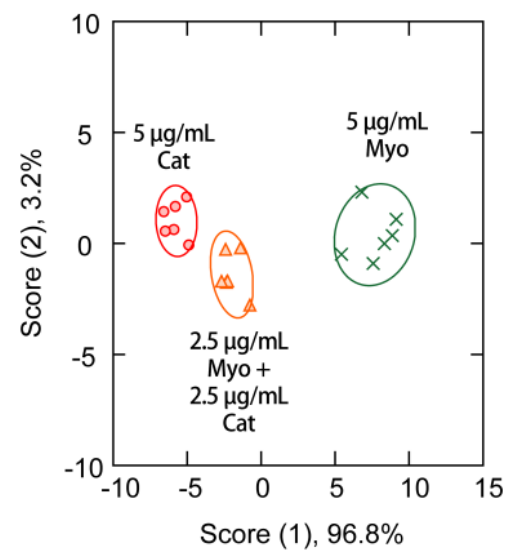

Figure 6. Discriminant score plot for (A) different concentrations of Cat $(0-5 \mu \mathrm{g} / \mathrm{mL})$, as well as (B) samples containing Cat and/or Myo with a total concentration of $5 \mu \mathrm{g} / \mathrm{mL}$ in the presence of human serum obtained from the seven-channel system consisting of $100 \mu \mathrm{g} / \mathrm{mL} \mathrm{nGO}$ and $20 \mathrm{nM}$ of the three fluorophore-modified ssDNAs, whereby ellipsoids represent confidence intervals $( \pm 1 \mathrm{SD})$ for the individual analytes. 


\section{Conclusions}

We have developed a multi-fluorescent ssDNAs/nGO sensor for the discrimination of proteins. Using conjugates between nGO and three ssDNAs that differ with respect to the sequence and fluorophore, various proteins were successfully identified based on their fluorescence signatures generated from a single microplate well. This system can be easily tuned and extended, as sensor elements with the following properties are commercially available: (i) ssDNAs with different structures and functions; (ii) fluorophores with different optical properties. The accessibility and tunability of this sensing system stands in stark contrast to previously reported multichannel signature-based sensing systems that require laborious synthetic [33] and/or protein expression protocols [34-37]. Due to the high discriminatory power and simple format, the sensor system presented herein should represent a highly promising tool for a facile and fast characterization of proteins or protein mixtures.

Supplementary Materials: The following supplementary material is available online at www.mdpi.com/14248220/17/10/2194/s1, Table S1: Dataset matrix for the differences between the fluorescence intensity before and after the addition of $15 \mu \mathrm{g} / \mathrm{mL}$ of proteins generated from the multichannel ssDNAs/nGO system, Table S2: Blind test of 60 samples using the multichannel ssDNAs/nGO system, Table S3: Dataset matrix for the differences between the fluorescence intensity before and after the addition of different concentrations of Cat in the presence of human serum, generated from the multi-fluorescent nGO/ssDNA sensor, Table S4: Dataset matrix for the differences between the fluorescence intensity before and after the addition of Cat, Myo, and a 1:1 mixture $(w / w)$ in the presence of human serum, generated from the multi-fluorescent nGO/ssDNA sensor, Figure S1: Changes in the emission spectra of P1-FAM and P3-Cy5 (20 nM fluorophore-modified ssDNA) in the presence of different concentrations of nGO in PBS $(\mathrm{pH}=7.4)$, Figure S2: Fluorescence recovery of ssDNAs quenched with nGO upon addition of various concentrations of BSA, Figure S3: Sensing of proteins using the three-channel ssDNAs/nGO system.

Acknowledgments: This work was supported by JSPS KAKENHI grants JP16K14043 and JP17H04884.

Author Contributions: Shunsuke Tomita conceived and designed the experiments; Shunsuke Tomita and Sayaka Ishihara performed the experiments; Shunsuke Tomita and Sayaka Ishihara analyzed the data; and Shunsuke Tomita and Ryoji Kurita wrote the manuscript.

Conflicts of Interest: The authors declare no conflict of interest.

\section{References}

1. Mohammed, M.I.; Desmulliez, M.P. Lab-on-a-chip based immunosensor principles and technologies for the detection of cardiac biomarkers: A review. Lab Chip 2011, 11, 569-595. [CrossRef] [PubMed]

2. Kirsch, J.; Siltanen, C.; Zhou, Q.; Revzin, A.; Simonian, A. Biosensor technology: Recent advances in threat agent detection and medicine. Chem. Soc. Rev. 2013, 42, 8733-8768. [CrossRef] [PubMed]

3. Peng, H.P.; Lee, K.H.; Jian, J.W.; Yang, A.S. Origins of specificity and affinity in antibody-protein interactions. Proc. Natl. Acad. Sci. USA. 2014, 111, E2656-E2665. [CrossRef] [PubMed]

4. Askim, J.R.; Mahmoudi, M.; Suslick, K.S. Optical sensor arrays for chemical sensing: The optoelectronic nose. Chem. Soc. Rev. 2013, 42, 8649-8682. [CrossRef] [PubMed]

5. Peveler, W.J.; Yazdani, M.; Rotello, V.M. Selectivity and specificity: Pros and cons in sensing. ACS Sens. 2016, 1, 1282-1285. [CrossRef]

6. You, C.C.; Miranda, O.R.; Gider, B.; Ghosh, P.S.; Kim, I.B.; Erdogan, B.; Krovi, S.A.; Bunz, U.H.; Rotello, V.M. Detection and identification of proteins using nanoparticle-fluorescent polymer 'chemical nose' sensors. Nat. Nanotechnol. 2007, 2, 318-323. [CrossRef] [PubMed]

7. Li, X.; Wen, F.; Creran, B.; Jeong, Y.; Zhang, X.; Rotello, V.M. Colorimetric protein sensing using catalytically amplified sensor arrays. Small 2012, 8, 3589-3592. [CrossRef] [PubMed]

8. Chou, S.S.; De, M.; Luo, J.; Rotello, V.M.; Huang, J.; Dravid, V.P. Nanoscale graphene oxide (nGO) as artificial receptors: Implications for biomolecular interactions and sensing. J. Am. Chem. Soc. 2012, 134, 16725-16733. [CrossRef] [PubMed]

9. Zamora-Olivares, D.; Kaoud, T.S.; Dalby, K.N.; Anslyn, E.V. In-situ generation of differential sensors that fingerprint kinases and the cellular response to their expression. J. Am. Chem. Soc. 2013, 135, 14814-14820. [CrossRef] [PubMed] 
10. Lu, Y.; Liu, Y.; Zhang, S.; Wang, S.; Zhang, S.; Zhang, X. Aptamer-based plasmonic sensor array for discrimination of proteins and cells with the naked eye. Anal. Chem. 2013, 85, 6571-6574. [CrossRef] [PubMed]

11. Tomita, S.; Yoshimoto, K. Polyion complex libraries possessing naturally occurring differentiation for pattern-based protein discrimination. Chem. Commun. 2013, 49, 10430-10432. [CrossRef] [PubMed]

12. Tomita, S.; Soejima, T.; Shiraki, K.; Yoshimoto, K. Enzymatic fingerprinting of structurally similar homologous proteins using polyion complex library constructed by tuning PEGylated polyamine functionalities. Analyst 2014, 139, 6100-6103. [CrossRef] [PubMed]

13. Yuan, Z.; Du, Y.; Tseng, Y.T.; Peng, M.; Cai, N.; He, Y.; Chang, H.T.; Yeung, E.S. Fluorescent gold nanodots based sensor array for proteins discrimination. Anal. Chem. 2015, 87, 4253-4259. [CrossRef] [PubMed]

14. Galpothdeniya, W.I.S.; Fronczek, F.R.; Cong, M.; Bhattarai, N.; Siraj, N.; Warner, I.M. Tunable GUMBOS-based sensor array for label-free detection and discrimination of proteins. J. Mater. Chem. B 2016, 4, 1414-1422. [CrossRef]

15. Wang, M.; Ye, H.; You, L.; Chen, X. A supramolecular sensor array using lanthanide-doped nanoparticles for sensitive detection of glyphosate and proteins. ACS Appl. Mater. Interfaces 2016, 8, 574-581. [CrossRef] [PubMed]

16. Xu, S.; Gao, T.; Feng, X.; Fan, X.; Liu, G.; Mao, Y.; Yu, X.; Lin, J.; Luo, X. Near infrared fluorescent dual ligand functionalized $\mathrm{Au}$ NCs based multidimensional sensor array for pattern recognition of multiple proteins and serum discrimination. Biosens. Bioelectron. 2017, 97, 203-207. [CrossRef] [PubMed]

17. Tomita, S.; Ishihara, S.; Kurita, R. Environment-sensitive turn-on fluorescent polyamino acid: Fingerprinting protein populations with post-translational modifications. ACS Appl. Mater. Interfaces 2017, 9, 22970-22976. [CrossRef] [PubMed]

18. De, M.; Rana, S.; Akpinar, H.; Miranda, O.R.; Arvizo, R.R.; Bunz, U.H.F.; Rotello, V.M. Sensing of proteins in human serum using conjugates of nanoparticles and green fluorescent protein. Nat. Chem. 2009, 1, 461-465. [CrossRef] [PubMed]

19. Miranda, O.R.; Chen, H.T.; You, C.C.; Mortenson, D.E.; Yang, X.C.; Bunz, U.H.; Rotello, V.M. Enzyme-amplified array sensing of proteins in solution and in biofluids. J. Am. Chem. Soc. 2010, 132, 5285-5289. [CrossRef] [PubMed]

20. Xu, S.; Lu, X.; Yao, C.; Huang, F.; Jiang, H.; Hua, W.; Na, N.; Liu, H.; Ouyang, J. A visual sensor array for pattern recognition analysis of proteins using novel blue-emitting fluorescent gold nanoclusters. Anal. Chem. 2014, 86, 11634-11639. [CrossRef] [PubMed]

21. Motiei, L.; Pode, Z.; Koganitsky, A.; Margulies, D. Targeted protein surface sensors as a tool for analyzing small populations of proteins in biological mixtures. Angew. Chem. Int. Ed. 2014, 53, 9289-9293. [CrossRef] [PubMed]

22. Ran, X.; Pu, F.; Ren, J.; Qu, X. A CuS-based chemical tongue chip for pattern recognition of proteins and antibiotic-resistant bacteria. Chem. Commun. 2015, 51, 2675-2678. [CrossRef] [PubMed]

23. Chen, S.; Wei, L.; Chen, X.W.; Wang, J.H. Suspension array of ionic liquid or ionic liquid-quantum dots conjugates for the discrimination of proteins and bacteria. Anal. Chem. 2015, 87, 10902-10909. [CrossRef] [PubMed]

24. Sun, W.; Lu, Y.; Mao, J.; Chang, N.; Yang, J.; Liu, Y. Multidimensional sensor for pattern recognition of proteins based on DNA-gold nanoparticles conjugates. Anal. Chem. 2015, 87, 3354-3359. [CrossRef] [PubMed]

25. Tomita, S.; Niwa, O.; Kurita, R. Artificial modification of an enzyme for construction of cross-reactive polyion complexes to fingerprint signatures of proteins and mammalian cells. Anal. Chem. 2016, 88, 9079-9086. [CrossRef] [PubMed]

26. Wei, X.; Chen, Z.; Tan, L.; Lou, T.; Zhao, Y. DNA-catalytically active gold nanoparticle conjugates-based colorimetric multidimensional sensor array for protein discrimination. Anal. Chem. 2017, 89, 556-559. [CrossRef] [PubMed]

27. Xu, S.; Wu, Y.; Sun, X.; Wang, Z.; Luo, X. A multicoloured Au NCs based cross-reactive sensor array for discrimination of multiple proteins. J. Mater. Chem. B 2017, 5, 4207-4213. [CrossRef] 
28. Wu, P.; Miao, L.N.; Wang, H.F.; Shao, X.G.; Yan, X.P. A multidimensional sensing device for the discrimination of proteins based on manganese-doped ZnS quantum dots. Angew. Chem. Int. Ed. 2011, 50, 8118-8121. [CrossRef] [PubMed]

29. Sang, L.J.; Wang, H.F. Aminophenylboronic-acid-conjugated polyacrylic acid-Mn-doped ZnS quantum dot for highly sensitive discrimination of glycoproteins. Anal. Chem. 2014, 86, 5706-5712. [CrossRef] [PubMed]

30. Li, C.; Wu, P.; Hou, X. Plasma-assisted quadruple-channel optosensing of proteins and cells with Mn-doped ZnS quantum dots. Nanoscale 2016, 8, 4291-4298. [CrossRef] [PubMed]

31. Lu, Y.; Kong, H.; Wen, F.; Zhang, S.; Zhang, X. Lab-on-graphene: Graphene oxide as a triple-channel sensing device for protein discrimination. Chem. Commun. 2013, 49, 81-83. [CrossRef] [PubMed]

32. Margulies, D.; Hamilton, A.D. Protein recognition by an ensemble of fluorescent DNA G-quadruplexes. Angew. Chem. Int. Ed. 2009, 48, 1771-1774. [CrossRef] [PubMed]

33. Xu, Q.; Zhang, Y.; Tang, B.; Zhang, C.Y. Multicolor quantum dot-based chemical nose for rapid and array-free differentiation of multiple proteins. Anal. Chem. 2016, 88, 2051-2058. [CrossRef] [PubMed]

34. Li, X.; Kong, H.; Mout, R.; Saha, K.; Moyano, D.F.; Robinson, S.M.; Rana, S.; Zhang, X.; Riley, M.A.; Rotello, V.M. Rapid identification of bacterial biofilms and biofilm wound models using a multichannel nanosensor. ACS Nano 2014, 8, 12014-12019. [CrossRef] [PubMed]

35. Rana, S.; Le, N.D.; Mout, R.; Duncan, B.; Elci, S.G.; Saha, K.; Rotello, V.M. A multichannel biosensor for rapid determination of cell surface glycomic signatures. ACS Cent. Sci. 2015, 1, 191-197. [CrossRef] [PubMed]

36. Le, N.D.B.; Tonga, G.Y.; Mout, R.; Kim, S.T.; Wille, M.E.; Rana, S.; Dunphy, K.A.; Jerry, D.J.; Yazdani, M.; Ramanathan, R.; et al. Cancer cell discrimination using host-guest "doubled" arrays. J. Am. Chem. Soc. 2017, 139, 8008-8012. [CrossRef] [PubMed]

37. Rana, S.; Le, N.D.; Mout, R.; Saha, K.; Tonga, G.Y.; Bain, R.E.; Miranda, O.R.; Rotello, C.M.; Rotello, V.M. A multichannel nanosensor for instantaneous readout of cancer drug mechanisms. Nat. Nanotechnol. 2015, 10, 65-69. [CrossRef] [PubMed]

38. Pei, H.; Li, J.; Lv, M.; Wang, J.; Gao, J.; Lu, J.; Li, Y.; Huang, Q.; Hu, J.; Fan, C. A graphene-based sensor array for high-precision and adaptive target identification with ensemble aptamers. J. Am. Chem. Soc. 2012, 134, 13843-13849. [CrossRef] [PubMed]

39. Tomita, S.; Matsuda, A.; Nishinami, S.; Kurita, R.; Shiraki, K. One-step identification of antibody degradation pathways using fluorescence signatures generated by cross-reactive DNA-based arrays. Anal. Chem. 2017, 89, 7818-7822. [CrossRef] [PubMed]

40. Liu, J. Adsorption of DNA onto gold nanoparticles and graphene oxide: Surface science and applications. Phys. Chem. Chem. Phys. 2012, 14, 10485-10496. [CrossRef] [PubMed]

41. Tabachnick, B.G.; Fidell, L.S. Using Multivariate Statistics, 4th ed.; Allyn \& Bacon: Needham Heights, MA, USA, 2001.

42. Larisika, M.; Huang, J.; Tok, A.; Knoll, W.; Nowak, C. An improved synthesis route to graphene for molecular sensor applications. Mater. Chem. Phys. 2012, 136, 304-308. [CrossRef]

43. Chen, J.; Li, Y.; Huang, L.; Li, C.; Shi, G. High-yield preparation of graphene oxide from small graphite flakes via an improved Hummers method with a simple purification process. Carbon 2015, 81, 826-834. [CrossRef]

44. Liao, K.H.; Lin, Y.S.; Macosko, C.W.; Haynes, C.L. Cytotoxicity of graphene oxide and graphene in human erythrocytes and skin fibroblasts. ACS Appl. Mater. Interfaces 2011, 3, 2607-2615. [CrossRef] [PubMed]

45. Pan, S.; Aksay, I.A. Factors controlling the size of graphene oxide sheets produced via the graphite oxide route. ACS Nano 2011, 5, 4073-4083. [CrossRef] [PubMed]

46. Ding, Z.; Zhang, Z.; Ma, H.; Chen, Y. In vitro hemocompatibility and toxic mechanism of graphene oxide on human peripheral blood T lymphocytes and serum albumin. ACS Appl. Mater. Interfaces 2014, 6, 19797-19807. [CrossRef] [PubMed]

47. Adkins, J.N.; Varnum, S.M.; Auberry, K.J.; Moore, R.J.; Angell, N.H.; Smith, R.D.; Springer, D.L.; Pounds, J.G. Toward a human blood serum proteome: Analysis by multidimensional separation coupled with mass spectrometry. Mol. Cell Proteom. 2002, 1, 947-955. [CrossRef]

48. Kodydkova, J.; Vavrova, L.; Kocik, M.; Zak, A. Human catalase, its polymorphisms, regulation and changes of its activity in different diseases. Folia Biol. 2014, 60, 153-167. 
49. Sallach, S.M.; Nowak, R.; Hudson, M.P.; Tokarski, G.; Khoury, N.; Tomlanovich, M.C.; Jacobsen, G.; de Lemos, J.A.; McCord, J. A change in serum myoglobin to detect acute myocardial infarction in patients with normal troponin I levels. Am. J. Cardiol. 2004, 94, 864-867. [CrossRef] [PubMed]

50. Mayr, B.M.; Kohlbacher, O.; Reinert, K.; Sturm, M.; Gropl, C.; Lange, E.; Klein, C.; Huber, C.G. Absolute myoglobin quantitation in serum by combining two-dimensional liquid chromatography-electrospray ionization mass spectrometry and novel data analysis algorithms. J. Proteome Res. 2006, 5, 414-421. [CrossRef] [PubMed]

(C) 2017 by the authors. Licensee MDPI, Basel, Switzerland. This article is an open access article distributed under the terms and conditions of the Creative Commons Attribution (CC BY) license (http:// creativecommons.org/licenses/by/4.0/). 